Original research article

\title{
Role of infochemical mediated zooplankton grazing in a phytoplankton competition model
}

\author{
Nicola D. Lewis ${ }^{a, b, *}$, Mark N. Breckels ${ }^{b}$, Michael Steinke ${ }^{b}$, Edward A. Codling ${ }^{a, b}$ \\ ${ }^{a}$ Department of Mathematical Sciences, University of Essex, Wivenhoe Park, Colchester CO4 3SQ UK \\ ${ }^{\mathrm{b}}$ School of Biological Sciences, University of Essex, Wivenhoe Park, Colchester CO4 3SQ UK
}

\section{A R T I C L E I N F O}

\section{Article history:}

Received 25 June 2012

Received in revised form 18 October 2012

Accepted 22 October 2012

Available online $\mathrm{xxx}$

\section{Keywords:}

Infochemicals

Competition

Predation

Dimethylsulfide (DMS)

Food web interactions

Population dynamics

\begin{abstract}
A B S T R A C T
Infochemicals released by marine phytoplankton play important roles in food web interactions by influencing the feeding behavior and selectivity of zooplanktonic predators. Recent modeling efforts have focused on the role of such chemicals as toxic grazing deterrents in phytoplankton competition. However, infochemicals may also be utilized as grazing cues, leading predators to profitable foraging patches. Here we investigate the role of infochemical mediated zooplankton grazing in a standard 3species phytoplankton competition model, with the aim of further elucidating the ecological role of phytoplankton derived infochemicals. We then extend this to consider a more realistic 4-species model. The models produce a range of solutions depending on the strength of competition and microzooplankton grazing selectivity. Our key result is that infochemical chemoattractants, which increase the susceptibility of the producer to grazing, can provide a refuge for both competing phytoplankton species by attracting carnivorous copepods to consume microzooplankton grazers in a multi-trophic interaction. Our results indicate that infochemicals potentially have important consequences for the dynamics of marine food webs.
\end{abstract}

(c) 2012 Elsevier B.V. All rights reserved.

\section{Introduction}

Information-conveying chemicals (infochemicals) including kairomones, allelochemicals or pheromones play a crucial role in food web interactions. Such chemicals can be exploited by an individual in order to find prey or mates, or to avoid predators. Consequently, chemically mediated interactions can have a strong effect on community structure and population dynamics within an ecosystem (Hay, 2009).

In the marine environment chemicals released into the surroundings by small unicellular phytoplankton can have a range of consequences for their susceptibility to predation and competitive interactions. For example some infochemicals are known to affect the foraging behavior and selectivity of their zooplanktonic predators (Vos et al., 2006). These chemicals may take the form of toxins (e.g. Turner and Tester, 1997) or deterrents (e.g. Wolfe, 2000) which act as a defense mechanism to reduce grazing pressure. Equally, cellular exudates may enhance the ability of a zooplankter to locate its prey (Breckels et al., 2011; Strickler,

\footnotetext{
* Corresponding author at: School of Biological Sciences, University of Essex Wivenhoe Park, Colchester CO4 3SQ, UK.

E-mail addresses: ndlewi@essex.ac.uk (N.D. Lewis), mbreck@essex.ac.uk (M.N. Breckels), msteinke@essex.ac.uk (M. Steinke), ecodling@essex.ac.uk (E.A. Codling)
}

1982). Additionally, multi-trophic interactions may occur, where the grazing-induced release of chemicals into the surrounding environment attracts carnivorous predators, thereby reducing grazing pressure on the primary producer (Steinke et al., 2002). Such tri-trophic interactions are well described in terrestrial environments (e.g. Dicke, 1999) and were first identified in a marine benthic system by Coleman et al. (2007). However, the occurrence of infochemically mediated multi-trophic interactions in the plankton remains unresolved.

In the nutrient-dilute marine environment, where competition for resources is fierce, phytoplankton deterrents may reduce grazing pressure on the producing species. They therefore have the potential to make zooplankton select alternative prey and, consequently, increase grazing on competing phytoplankton species. Models investigating the effects of toxic phytoplankton on the outcome of grazing interactions in a mixed prey assemblage have recently received heightened research attention (e.g. Bairagi et al., 2008; Banerjee and Venturino, 2011; Pal et al., 2009; Roy et al., 2006; Roy and Chattopadhyay, 2006), whereas the role of grazer attraction to phytoplankton exudates has received little attention.

Numerous infochemicals exist in the marine environment. We used the secondary algal metabolite dimethylsulfonio propionate (DMSP) and its breakdown product dimethyl sulfide (DMS) as example infochemicals to explore potential planktonic 
interactions across three trophic levels, since a wide body of evidence suggests that these chemicals play an important role in foraging behavior and predator-prey interactions (Breckels et al., 2011; Seymour et al., 2010; Strom et al., 2003a,b; Wolfe et al., 1997). Microzooplankton are major grazers of phytoplankton (Calbet and Landry, 2004; Sherr and Sherr, 1988), however, the influence of DMS and related compounds on microzooplankton grazing remains contentious; some experimental evidence suggests that these chemicals cause grazing inhibition (e.g. Strom et al., 2003a,b; Wolfe et al., 1997) and other more recent studies suggest they act as chemoattractants (e.g. Breckels et al., 2011; Seymour et al., 2010). The production of DMS is rapidly accelerated following microzooplankton grazing on phytoplankton (Archer et al., 2001a; Wolfe and Steinke, 1996). DMS has been shown to elicit behavioral changes in a wide range of marine organisms including planktonic copepods (Steinke et al., 2006). The ability of copepods to react to DMS suggests that, in principle, the grazing-induced release of DMS can promote multi-trophic interactions between phytoplankton, microzooplankton and copepods by providing an infochemical cue for foraging copepods. This may then enhance predation on microzooplankton and thereby release grazing pressure on phytoplankton (Steinke et al., 2002).

We recently explored a model of the interactions between infochemical producing phytoplankton, microzooplankton and copepods under the influence of a DMS infochemical cue produced following microzooplankton grazing (Lewis et al., 2012). Firstly, we found that the inclusion of a grazing-induced infochemical term, that acted to attract predatory copepods, could stabilize the population dynamics. Secondly, we found that the inclusion of such a term could promote the formation of phytoplankton blooms. Irigoien et al. (2005) proposed that bloom propagation occurs due to a loophole in the microzooplankton grazing impact, thus supporting the notion that infochemicals have important consequences for the dynamics of marine systems. Here we build on the work of Lewis et al. (2012) by including a competing noninfochemical producing phytoplankton species. First, we consider a standard two-competitor, one predator model adapted to represent the interactions between infochemical and non-infochemical producing phytoplankton, microzooplankton and copepods (Fig. 1). We then extend this to consider a more realistic 4species model and show that the same qualitative results are obtained. The case where infochemicals act as deterrents or toxins has been well studied elsewhere (e.g. Roy et al., 2006) and hence we focus our efforts on the case where infochemical exudates enhance microzooplankton foraging, with the aim of further elucidating the ecological function of chemoattractants in the plankton.

\section{The model}

We consider a system where microzooplankton $(M)$ graze on two distinct competing populations of phytoplankton: $P_{1}$ are infochemical producing phytoplankton, for example dinoflagellates or coccolithophores which produce increased levels of DMS during microzooplankton grazing (Archer et al., 2003; Wolfe and Steinke, 1996), and $P_{2}$ are 'non-infochemical' producing phytoplankton. Phytoplankton are grazed by microzooplankton, which are then in turn consumed by copepods. Although copepods can feed on small phytoplankton, studies on the grazing rates of Calanus helgolandicus and $C$. finmarchicus have shown that the small DMS-producing coccolithophore Emiliania huxleyi is a suboptimal food source (Nejstgaard et al., 1995). Microzooplankton grazers may play an important role in the energy flow and 'trophic upgrading' by enhancing the biochemical content of phytoplankton (Klein Breteler et al., 1999; Tang and Taal, 2005).

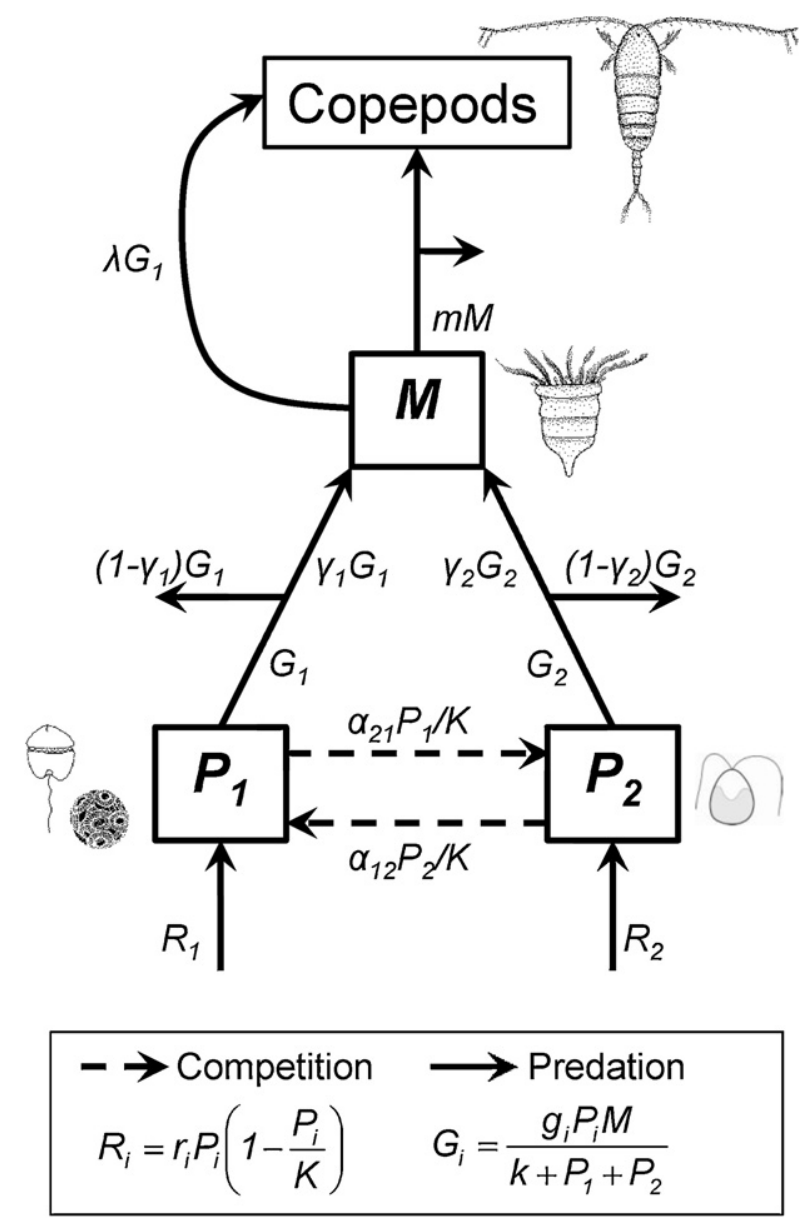

Fig. 1. The interactions between infochemical producing phytoplankton $\left(P_{1}\right)$, noninfochemical producing phytoplankton $\left(P_{2}\right)$, microzooplankton $(M)$ and copepods for the model given by Eqs. (1)-(3). The solid arrows show the flow of energy through predation, phytoplankton uptake of nutrients and losses from the system. The dashed arrows show phytoplankton competition. $R_{i}$ are the phytoplankton growth terms while $G_{i}$ are the microzooplankton grazing terms. Parameter definitions are given in Table 1.

One of the key assumptions in the following model is that microzooplankton provide the only trophic link between phytoplankton and copepods.

A simple representation of the above system can be provided by a two-competitor, one predator model, such as that employed by Kretzschmar et al. (1993). The authors of this paper investigated the effects of adding an inedible algal species to a system consisting of an edible algal species with a zooplankton grazer. The model detailed below is topologically equivalent to that of Kretzschmar et al.(1993). However, their assumption that one of the phytoplankton species is inedible means that their numerical simulations were carried out on a simplified model, as described below.

Both phytoplankton species grow logistically where $r_{1}$ and $r_{2}$ are the intrinsic rates of growth and $K_{1}$ and $K_{2}$ are the carrying capacities of infochemical producing and non-infochemical producing phytoplankton, respectively. Phytoplankton growth is assumed to be limited by nutrients and light availability. Phytoplankton growth is also limited by an interspecific competition term, where $\alpha_{12}$ is the competitive effect of non-infochemical producers on infochemical producers and vice versa (Fig. 1). The $\alpha$ terms are assumed to represent growth limiting factors such as nutrient depletion and/or shading by the other species (Solé et al., 2006), but may also account for competitive advantages due to differences in size and physiology. 
The Holling type II functional response used by Kretzschmar et al. (1993) to model microzooplankton grazing is presented here in Michaelis-Menten form, which is typically used to represent microzooplankton feeding (Davidson et al., 2011; Roberts et al., 2011). The maximum grazing rates of microzooplankton on infochemical and non-infochemical producing phytoplankton are $g_{1}$ and $g_{2}$ respectively while $k$ is the half saturation constant. One of the consequences of assuming inedible phytoplankton, $i$, is that $g_{i}=0$. All terms multiplied by the grazing rate on inedible algae in the Kretzschmar et al. (1993) model cancel upon applying this assumption, meaning that their numerical simulations were carried out on a reduced model. Here, both infochemical and noninfochemical producing phytoplankton are edible, although subject to differing grazing rates through microzooplankton selectivity, and hence $g_{1}, g_{2}>0$. We further impose the constraint that $g_{1}+g_{2}=g_{\max }$ where $g_{\max }$ is some constant maximum microzooplankton grazing rate. This constraint means that an increase in the grazing rate on one phytoplankton species, based on phytoplankton infochemical characteristics, will correspond to a decrease of grazing on the other. Hence when $g_{1}=g_{2}$ microzooplankton show no grazing selectivity but when $g_{1}>g_{2}$ infochemicals act as grazing attractors, resulting in increased microzooplankton grazing on infochemical producing phytoplankton. It should be noted that the saturation of the grazing response is dependent on the abundances of both phytoplankton species. Therefore, total microzooplankton grazing selectivity is based both on the attractiveness, dependent on infochemical characteristics, and abundance of each phytoplankton species.

A key point to note is that although copepods are not explicitly modeled here, the effect of copepod predation is accounted for in the microzooplankton mortality terms in Eq. (3). Contrary to studies on toxic phytoplankton (e.g. Roy et al., 2006), DMS has no toxic effects on microzooplankton grazers (Strom et al., 2003a,b) and therefore grazing infochemical producing phytoplankton has no direct harmful effect for microzooplankton. However, microzooplankton mortality is indirectly increased by a factor $\lambda$ proportional to grazing on infochemical producing phytoplankton. Such a term has typically been used to represent the inhibitory effects of toxic phytoplankton in similar models (e.g. Banerjee and Venturino, 2011; Pal et al., 2009; Roy et al., 2006; Roy and Chattopadhyay, 2006). However, here this mortality is assumed to be from an instantaneous increase in predation by copepods attracted by elevated levels of infochemicals in the system, where the parameter $\lambda$ is a non-dimensional quantity relating the microzooplankton grazing rate to the infochemical-mediated microzooplankton mortality rate (Lewis et al., 2012; Steinke et al., 2006). The mortality term $m$ represents any mortality incurred by microzooplankton in the absence of infochemicals; this microzooplankton mortality is mainly assumed to be from predation by copepods (mediated through mechanisms other than chemoreception), however, this term also includes a background mortality through processes such as sinking and predation from higher trophic levels.

The model is given by:

$$
\begin{aligned}
& \frac{d P_{1}}{d t}=r_{1} P_{1}\left(1-\frac{P_{1}+\alpha_{12} P_{2}}{K_{1}}\right)-\frac{g_{1} P_{1} M}{k+P_{1}+P_{2}} \\
& \frac{d P_{2}}{d t}=r_{2} P_{2}\left(1-\frac{P_{2}+\alpha_{21} P_{1}}{K_{2}}\right)-\frac{g_{2} P_{2} M}{k+P_{1}+P_{2}} \\
& \frac{d M}{d t}=\frac{\left(\gamma_{1}-\lambda\right) g_{1} P_{1} M+\gamma_{2} g_{2} P_{2} M}{k+P_{1}+P_{2}}-m M
\end{aligned}
$$

where $P_{1} \geq 0, P_{2} \geq 0, M \geq 0$ and all model parameters are nonnegative and constant in time. Table 1 summarizes the variables and parameters in this model while Fig. 1 shows the interactions between the plankton species.

\section{Mathematical results}

The dynamics of the one- and two-dimensional subsystems of Eqs. (1)-(3) are well known (Kretzschmar et al., 1993). If $P_{i} \neq 0$ and $P_{j}, M \equiv 0$ then $P_{i}$, in the absence of competition or predation, will grow to the environmental carrying capacity. For $M \equiv 0$ and $P_{1}$, $P_{2} \neq 0$ the model reduces to the standard Lotka-Volterra competition model (Murray, 2002; Waltman, 1983), where stability is only possible if the competition between the two phytoplankton species is weak $\left(\alpha_{12}, \alpha_{21}<1\right)$. If $P_{j} \equiv 0$ and $P_{i}, M \neq 0$ the model reduces to the standard Rosenzweig-MacArthur predator-prey equations (Rosenzweig and MacArthur, 1963) where the system can be destabilized by the phytoplankton carrying capacity.

A stability analysis of the full model given by Eqs. (1)-(3) has been carried out by Kretzschmar et al. (1993). The model possesses seven different equilibrium points of the form $E_{i}=\left(P_{1}^{*}, P_{2}^{*}, M^{*}\right)$. These equilibria, along with their stability conditions, are summarized in Table 2. The reader is referred to Kretzschmar et al. (1993) for full mathematical details.

\section{Numerical results}

MATLAB 7.8 (MathWorks Inc., 2009) is used to numerically investigate the qualitative effect of infochemical-mediated microzooplankton grazing on the population dynamics of the system. We go beyond previous studies, which have solely focused on the specific cases where infochemical producing phytoplankton are

\begin{tabular}{|c|c|c|c|}
\hline Variable/parameter & Definition & Value & Reference \\
\hline$P_{1}$ & Infochemical producing phytoplankton & - & - \\
\hline$P_{2}$ & Non-infochemical producing phytoplankton & - & - \\
\hline$M$ & Microzooplankton & - & - \\
\hline$r_{1}$ & Intrinsic growth rate of $P_{1}$ & $0.47 \mathrm{~d}^{-1}$ & Wolfe and Steinke (1996) \\
\hline$r_{2}$ & Intrinsic growth rate of $P_{2}$ & $0.7 d^{-1}$ & Wolfe and Steinke (1996) \\
\hline$K_{i}, i=1,2$ & Phytoplankton carrying capacity & $120 \mu \mathrm{gCl}{ }^{-1}$ & Morozov et al. (2011) \\
\hline$\alpha_{12}$ & Competitive effect of $P_{2}$ on $P_{1}$ & $0.8 ; 1.2$ & - \\
\hline$\alpha_{21}$ & Competitive effect of $P_{1}$ on $P_{2}$ & $0.8 ; 1.2$ & - \\
\hline$g_{1}$ & Microzooplankton grazing rate on $P_{1}$ & $3 \mu g C l^{-1} d^{-1}$ & - \\
\hline$g_{2}$ & Microzooplankton grazing rate on $P_{2}$ & $3 \mu \mathrm{gCl}^{-1} \mathrm{~d}^{-1}$ & - \\
\hline$g_{\max }$ & Maximum grazing rate & $6 \mu \mathrm{gCl}^{-1} \mathrm{~d}^{-1}$ & Morozov et al. (2011) \\
\hline$k$ & Half saturation constant & $20 \mu \mathrm{gCl}^{-1}$ & Morozov et al. (2011) \\
\hline$\gamma_{i}, i=1,2$ & Microzooplankton grazing efficiency & 0.25 & Edwards and Brindley (1999) \\
\hline$m$ & Microzooplankton mortality (no infochemicals) & $0.3 d^{-1}$ & Lewis et al. (2012) \\
\hline$\lambda$ & Additional microzooplankton mortality & 0.1 & Lewis et al. (2012) \\
\hline
\end{tabular}

Table 1

The variables and parameters used in the model given by Eqs. (1)-(3). The parameter values given here are fixed unless otherwise stated. 
Table 2

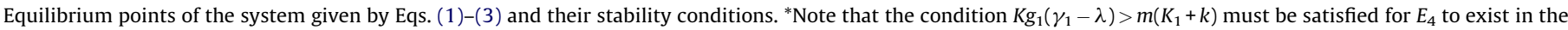
positive octant. An analogous condition exists for the existence of $E_{5}$ in the positive octant.

\begin{tabular}{|c|c|c|}
\hline Equilibrium & $P_{1}^{*}, P_{2}^{*}, M^{*}$ & Stability conditions \\
\hline$E_{0}$ & $0,0,0$ & Unstable \\
\hline$E_{1}$ & $K_{1}, 0,0$ & $\begin{array}{l}1<\alpha_{21} \frac{K_{1}}{K_{2}} \\
\frac{\left(\gamma_{1}-\lambda\right) g_{1} K_{1}}{k+K_{1}}<m\end{array}$ \\
\hline$E_{2}$ & $0, K_{2}, 0$ & $\begin{array}{l}1<\alpha_{12} \frac{K_{2}}{K_{1}} \\
\frac{\gamma_{2} g_{2} K_{2}}{k+K_{2}}<m\end{array}$ \\
\hline$E_{3}$ & $\frac{K_{1}-\alpha_{12} K_{2}}{1-\alpha_{12} \alpha_{21}}, \frac{K_{2}-\alpha_{21} K_{1}}{1-\alpha_{12} \alpha_{21}}, 0$ & $\begin{array}{l}\alpha_{12}, \alpha_{21}<1 \\
\frac{\left(\gamma_{1}-\lambda\right) g_{1} P_{1}^{*}+\gamma_{2} g_{2} P_{2}^{*}}{k+P_{1}^{*}+P_{2}^{*}}<m\end{array}$ \\
\hline$E_{4}{ }^{*}$ & $\frac{m k}{g_{1}\left(\gamma_{1}-\lambda\right)-m}, 0, \frac{r_{1} k\left(\gamma_{1}-\lambda\right)\left(K_{1}\left(g_{1}\left(\gamma_{1}-\lambda\right)-m\right)-m k\right)}{K_{1}\left(g_{1}\left(\gamma_{1}-\lambda\right)-m\right)^{2}}$ & $\begin{array}{l}r_{2}\left(1-\frac{\alpha_{21} P_{1}^{*}}{K_{2}}\right)-\frac{g_{2} M^{*}}{k+P_{1}^{*}}<0 \\
\frac{K_{1} g_{1} M^{*}}{\left(k+P_{1}^{*}\right)^{2}}<r_{1}\end{array}$ \\
\hline$E_{5}{ }^{*}$ & $0, \frac{m k}{\gamma_{2} g_{2}-m}, \frac{r_{2} k \gamma_{2}\left(K_{2}\left(\gamma_{2} g_{2}-m\right)-m k\right)}{K_{2}\left(\gamma_{2} g_{2}-m\right)^{2}}$ & $\begin{array}{l}r_{1}\left(1-\frac{\alpha_{12} P_{2}^{*}}{K_{1}}\right)-\frac{g_{1} M^{*}}{k+P_{2}^{*}}<0 \\
K_{2} g_{2} M^{*}\end{array}$ \\
\hline$E_{6}$ & $P_{1}, P_{2}, M \neq 0$ & \\
\hline
\end{tabular}

avoided or not grazed at all, to consider infochemicals as attractants, which cause the producer to be grazed more heavily than its competitor. When microzooplankton grazers are not present Eqs. (1)-(3) reduce to the standard Lotka-Volterra competition model (Murray, 2002; Waltman, 1983). The LotkaVolterra competition model is well known to exhibit four qualitatively different behaviors depending on the strength of the competitive effect of each of the phytoplankton species on the other i.e. weak competition $\alpha_{12}, \alpha_{21}<1$, strong competition $\alpha_{12}$, $\alpha_{21}>1$, infochemical producing phytoplankton as the superior competitors $\alpha_{12}<1, \alpha_{21}>1$ and non-infochemical producing phytoplankton as the superior competitors $\alpha_{12}>1, \alpha_{21}<1$ (see Murray, 2002). In the following analysis the competition between the two phytoplankton species is parameterized for each of the four competition situations and the effect of adding (i) a microzooplankter which shows no grazing selectivity $\left(g_{1}=g_{2}\right)$ and (ii) a microzooplankter which exhibits grazing selectivity in response to infochemical cues is investigated. The case where infochemicals act as deterrents or toxins has been well studied elsewhere (e.g. Roy et al., 2006) and hence these results have been omitted. Here we focus on the case where infochemicals act as grazing attractors $\left(g_{1}>g_{2}\right)$, as observed in the experiments of Seymour et al. (2010) and Breckels et al. (2011).

Table 1 gives the parameter values used in the numerical analysis, which are fixed unless otherwise stated. These values were taken from parameter ranges found in the literature to give biologically reasonable results. It should be noted that in the following analysis the infochemical producing phytoplankton have been parameterized with a lower intrinsic growth rate than the non-infochemical producing phytoplankton. This is based on the experiments of Wolfe and Steinke (1996) who compared the growth and DMS production rates of two different strains of the phytoplankton species Emiliania huxleyi and found the high DMS producing strain to achieve lower growth rates. Here we assume that the lower growth rate corresponds to a cost of producing infochemicals.

\subsection{Microzooplankton show no response to infochemicals}

The presence of generalist microzooplankton grazers that show no grazing selectivity for either phytoplankton species results in the extinction of infochemical producing phytoplankton. This is a consequence of reduced growth rates as a cost of infochemical production.

For all cases where microzooplankton show no grazing selectivity $\left(g_{1} / g_{\max }=0.5\right)$ solutions tend to a stable limit cycle around the saddle-focus $E_{5}$ on the $P_{2}-M$ plane (Fig. 2a). In this situation the infochemical producing phytoplankton become extinct from the system in less than 50 days, leaving the noninfochemical producing phytoplankton and microzooplankton to exhibit predator-prey oscillations over time (Fig. 2b), such that there is a recurring bloom of non-infochemical producing phytoplankton.

\subsection{Microzooplankton use chemoattractors}

To model microzooplankton grazing selectivity, bifurcation analyses were carried out in Matcont (Dhooge et al., 2003) for each of the competition situations. All parameters were fixed at the values given in Table 1 except for the microzooplankton grazing rates, $g_{1}$ and $g_{2}$ (where $g_{2}=g_{\max }-g_{1}$ ), which were allowed to vary from 0 to $g_{\max }$ to model microzooplankton deterrence $\left(g_{1}<g_{\max / 2}\right.$; results analogous to Roy et al. (2006)) and attraction $\left(g_{1}>g_{\max } / 2\right)$ in response to infochemical cues. For simplicity, in the following analysis the rescaled parameter $g$ (where $0 \leq g=g_{1} / g_{\max } \leq 1$ ) is used to represent microzooplankton grazing selectivity for infochemical producing phytoplankton. Selected results of this analysis are summarized in the bifurcation diagrams given by Figs. 3-5.

When infochemicals were modeled as grazing attractors the infochemical producers were driven to extinction in most cases as a result of increased grazing pressure from microzooplankton (bifurcation diagrams omitted). However, the key result is that, despite lower growth rates and increased grazing pressure, phytoplankton coexistence was possible when both the competitive effect of non-infochemical producers was weak $\left(\alpha_{12}=0.8\right)$ and the grazing attractance was strong ( $g>0.765$; Figs. 3 and 4$)$.

For both cases where non-infochemical producers are weak competitors $\left(\alpha_{12}=0.8\right.$ ), increasing the microzooplankton grazing selectivity for infochemical producing phytoplankton (from $g=0.5$ ) results in a supercritical Hopf bifurcation at $g=0.720$. This Hopf bifurcation destroys the stable limit cycle emanating 


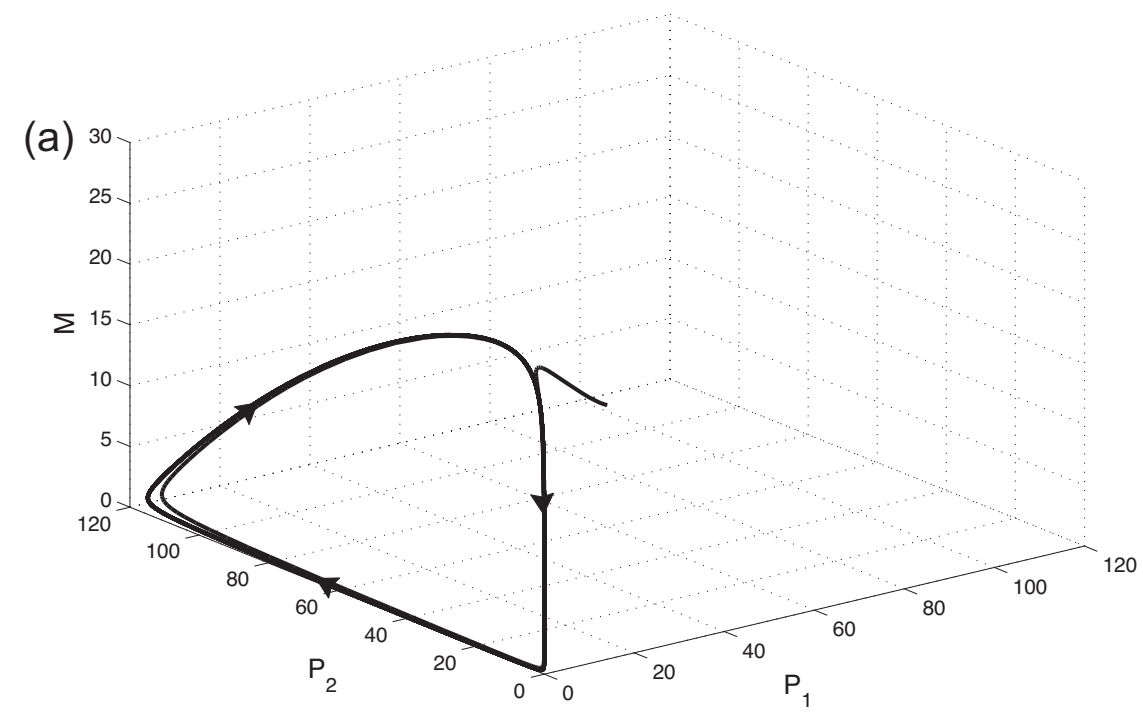

(b)

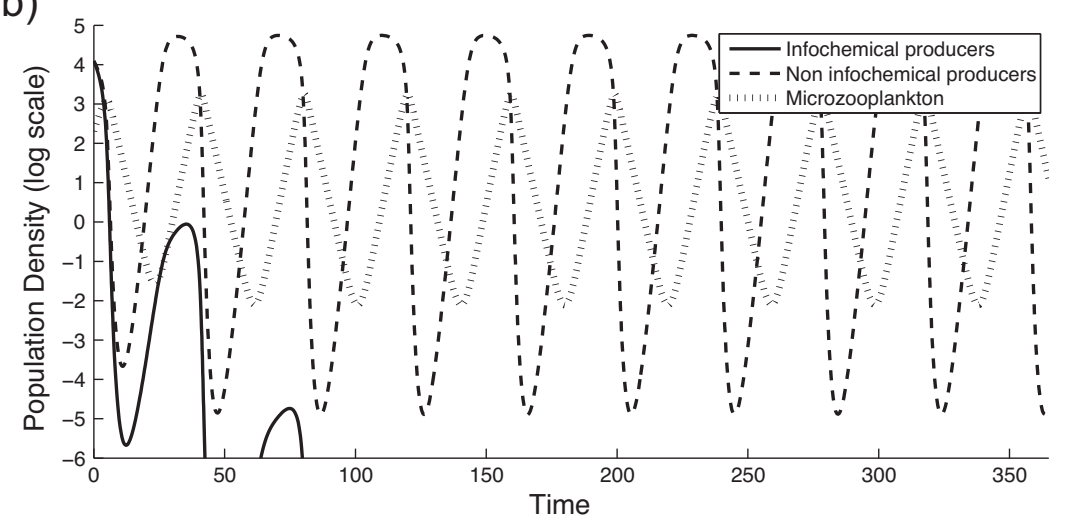

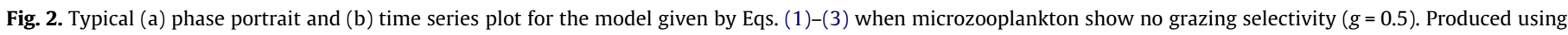
competition values $\alpha_{12}=\alpha_{21}=0.8$.

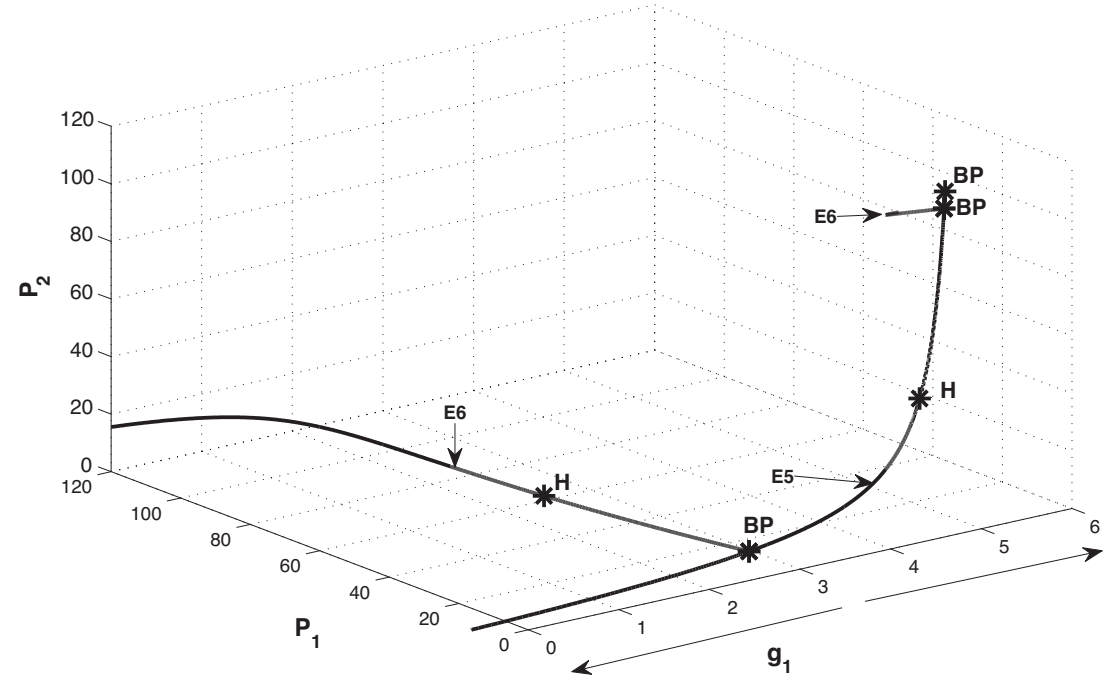

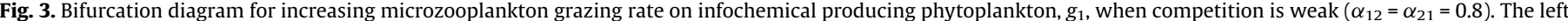

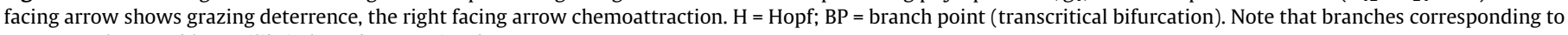
permanently unstable equilibria have been omitted.

Please cite this article in press as: Lewis, N.D., et al., Role of infochemical mediated zooplankton grazing in a phytoplankton competition model. Ecol. Complex. (2012), http://dx.doi.org/10.1016/j.ecocom.2012.10.003 


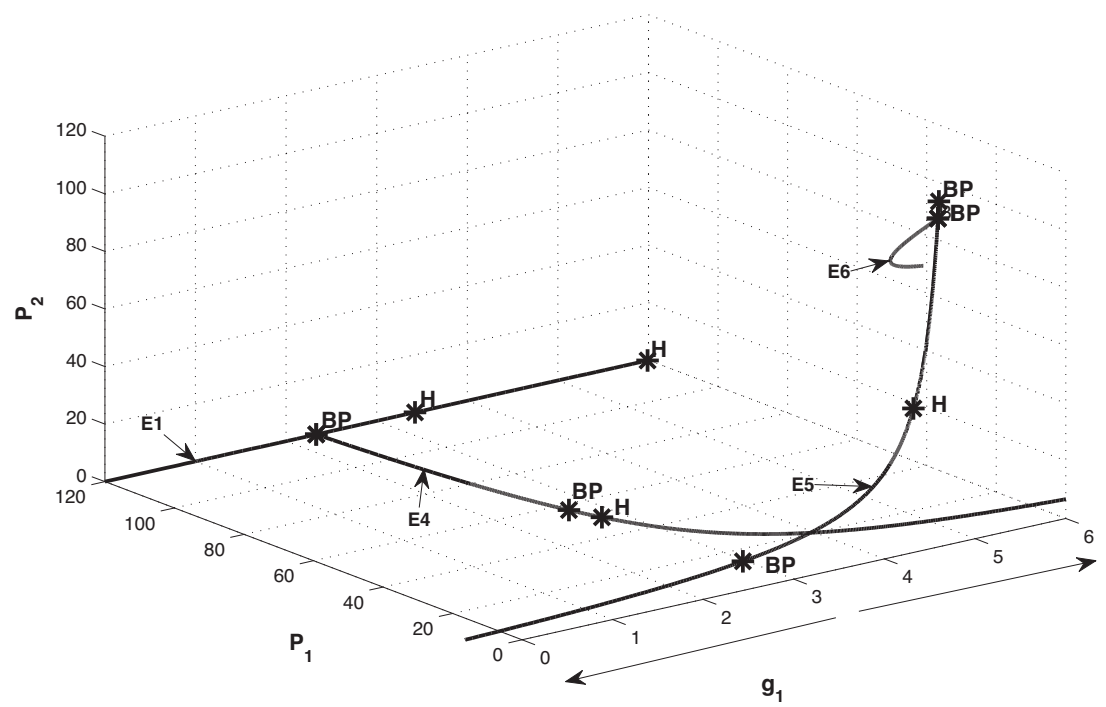

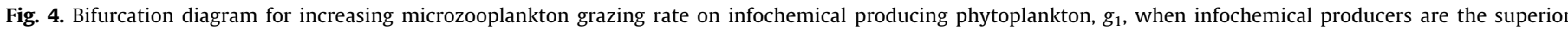

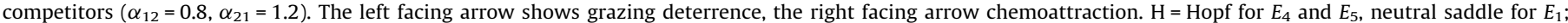
$\mathrm{BP}=$ branch point (transcritical bifurcation). Note that branches corresponding to permanently unstable equilibria have been omitted.
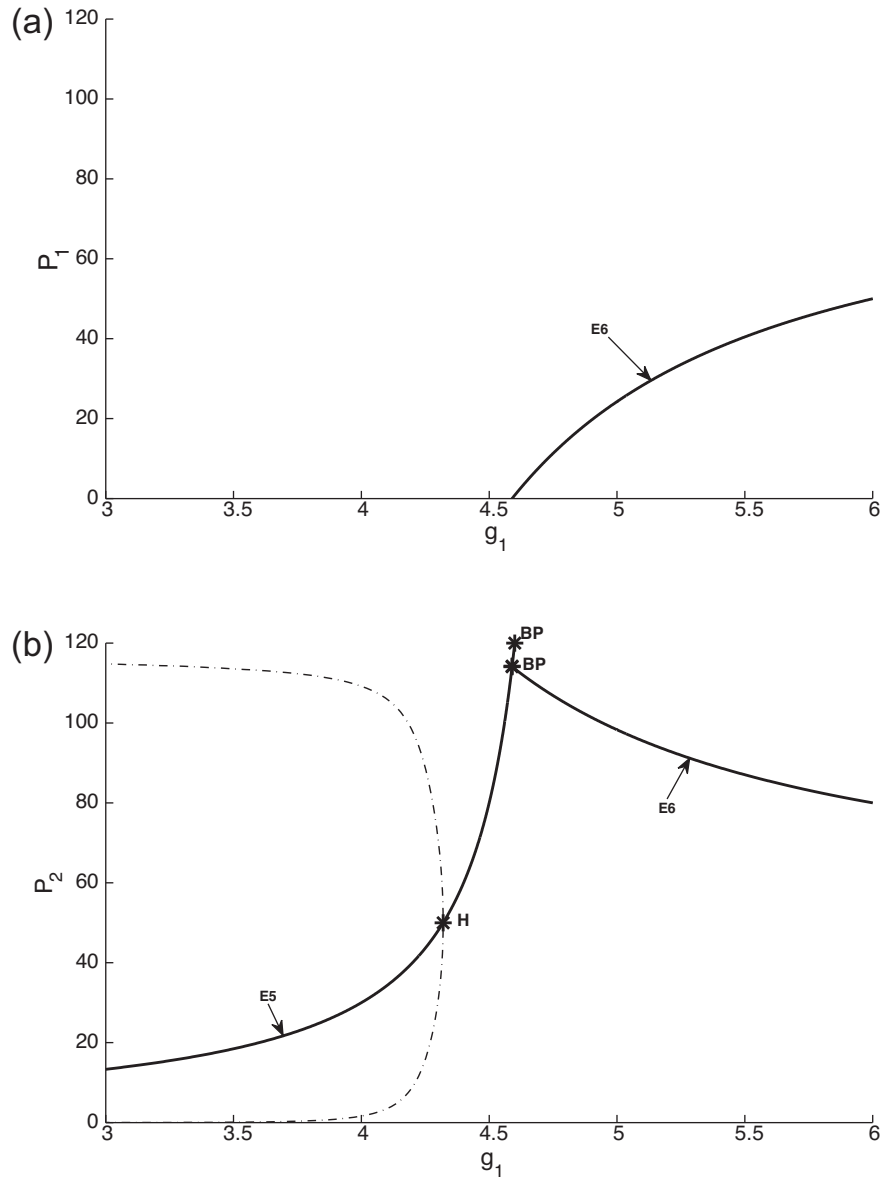

Fig. 5. Bifurcation diagram for (a) $P_{1}$ and (b) $P_{2}$ when microzooplankton chemoattraction is increased and competition is weak $\left(\alpha_{12}=\alpha_{21}=0.8\right)$. The dotdashed line shows the magnitude of the limit cycle when $E_{5}$ is a saddle-focus. $\mathrm{H}=$ Hopf; $\mathrm{BP}=$ branch point (transcritical bifurcation). A similar diagram is obtained when infochemical producers are parameterized as the superior competitors $\left(\alpha_{12}=0.8, \alpha_{21}=1.2\right)$. Note that branches corresponding to permanently unstable equilibria have been omitted. from $E_{5}$ and transforms $E_{5}$ from a saddle-focus to a stable node (Fig. 5b), so that non-infochemical producing phytoplankton and microzooplankton populations tend to a stable steady state. A further transcritical bifurcation at $g=0.765$ transforms $E_{5}$ into a saddle point and transfers stability to $E_{6}$ (Fig. 5 ), which is a stable focus-node corresponding to the coexistence of all plankton species (Fig. 6).

\subsubsection{Persistence}

The method of Freedman and Waltman (1984) was used to test for persistence when the competitive effect of non-infochemical producers is weak $\left(\alpha_{12}=0.8\right)$ and chemoattraction is strong $(g>0.765)$, that is when coexistence is possible in the model. The model given by equations (1)-(3) is of the form of model (3.2) of Freedman and Waltman (1984), hence the equations are continuous and bounded in forward time. $E_{0}$ is always a hyperbolic saddle point (Table 2). It can also be shown that $E_{1}$ and $E_{2}$ are hyperbolic saddle points for the conditions under consideration. To prove persistence, it is further required that all boundary equilibria repel trajectories orthogonally to their coordinate planes. By theorem 3.1 of Freedman and Waltman (1984), provided no limit cycles exist in the boundary planes, this gives conditions:

$r_{1}\left(1-\frac{\alpha_{12} \tilde{P}_{2}}{K_{2}}\right)-\frac{g_{1} \tilde{M}}{k+\tilde{P}_{2}}>0$

$r_{2}\left(1-\frac{\alpha_{21} \hat{P}_{1}}{K_{1}}\right)-\frac{g_{2} \hat{M}}{k+\hat{P}_{1}}>0$

$\frac{\left(\gamma_{1}-\lambda\right) g_{1} P_{1}^{*}+\gamma_{2} g_{2} P_{2}^{*}}{k+P_{1}^{*}+P_{2}^{*}}-m>0$

where $E_{3}=\left(P_{1}^{*}, P_{2}^{*}, 0\right), E_{4}=\left(\hat{P}_{1}, 0, \hat{M}\right)$ and $E_{5}=\left(0, \tilde{P}_{2}, \tilde{M}\right)$.

It can be shown that each of the above conditions are satisfied for the parameter values under consideration. However, the Dulac 


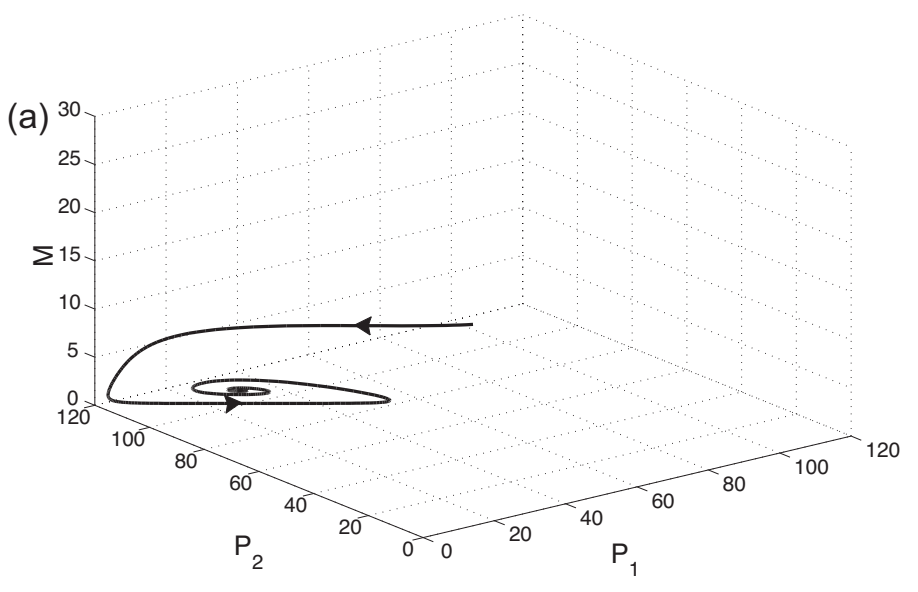

(b)

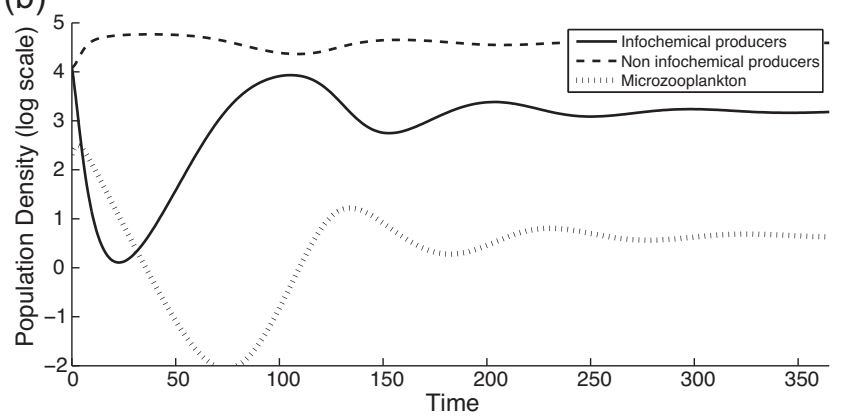

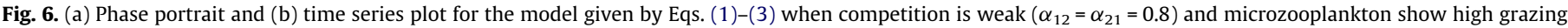
attraction $(g=0.833)$. Similar plots are obtained when infochemical producers are parameterized as the superior competitors $\left(\alpha_{12}=0.8, \alpha_{21}=1.2\right)$.

criterion could not be satisfied for $E_{4}$. Furthermore, the Jacobian matrix corresponding to this equilibrium possesses a complex conjugate pair of eigenvalues with positive real part. This suggests the existence of a limit cycle in the $P_{1}-M$ plane. The existence of this limit cycle does not disprove persistence. However, testing for persistence becomes more complicated (Freedman and Waltman, 1984 ) and is beyond the scope of this paper.

The fact that coexistence is possible, and persistence likely, suggests that infochemical attractants may play a beneficial role for the producing species under certain conditions. This presents a counterintuitive result; chemoattractants act to lead microzooplankton to the producing phytoplankton cells, resulting in an increased mortality from grazing. However, the release of infochemicals following grazing by microzooplankton attracts predatory copepods that diminish microzooplankton populations. This creates a refuge from grazing at the population level for the infochemical producing phytoplankton, as well as for the noninfochemical producers. In this situation, the long term benefit of producing chemicals to attract copepods outweigh the short term cost of increasing their attractiveness to microzooplankton grazers.

\section{Model evaluation and refinements}

The model given by Eqs. (1)-(3) is a simple representation of the system under investigation, employed to make analytic progress (e.g. Kretzschmar et al., 1993). In particular, an important feature of the system is copepod predation on microzooplankton, which is included only explicitly in the linear microzooplankton mortality terms given by Eq. (3). Generally, any mortality caused by higher trophic levels is modeled by a nonlinear term, although the linear form is commonly used in the absence of evidence to suggest otherwise (Edwards and Yool, 2000).
A more realistic representation of the system can be obtained by adding an equation for the copepod dynamics and modifying the microzooplankton mortality terms accordingly. Taking this approach, Eqs. (1) and (2) remain unchanged. Copepods consume microzooplankton according to a Michaelis-Menten functional response, parameterized with a lower maximum consumption rate and higher half saturation density as copepods evolve on slower time scales than small microzooplankton grazers (Edwards et al., 2000). This predation rate is increased by a multiplicative factor $1+\left(\xi g_{1} P_{1} M\right) /\left(1+P_{1}+P_{2}\right)$ to represent an increase in copepod foraging efficiency through the use of grazing-induced infochemicals, where the parameter $\xi$ represents how much an increase in infochemicals corresponds to an increase in copepod predation (Lewis et al., 2012). Microzooplankton natural mortality (no predation from copepods) is represented by the parameter $\mu$, while copepods suffer density dependent mortality at a rate $\delta$, which corresponds to predation from higher trophic levels.

The modified microzooplankton and new copepod equations are given by:

$\frac{d M}{d t}=\frac{\gamma_{1} g_{1} P_{1} M+\gamma_{2} g_{2} P_{2} M}{k+P_{1}+P_{2}}-\mu M-\frac{\beta M Z}{k_{Z}+M}\left(1+\frac{\xi g_{1} P_{1} M}{k+P_{1}+P_{2}}\right)$

$\frac{d Z}{d t}=\frac{\epsilon \beta M Z}{k_{Z}+M}\left(1+\frac{\xi g_{1} P_{1} M}{k+P_{1}+P_{2}}\right)-\delta Z^{2}$

where $M \geq 0, Z \geq 0$ and all model parameters are nonnegative and constant in time. Table 3 summarizes the additional variables and parameters in the modified model.

We do not carry out a full equilibrium and stability analysis on the more complex model Eqs. (1), (2), (7) and (8). Rather, we use numerical simulations and bifurcation analyses to show that the 
Table 3

The variables and parameters used for copepods in the refined model given by Eqs. (7)-(8). The parameter values given here are fixed unless otherwise stated.

\begin{tabular}{|c|c|c|c|}
\hline Variable/ parameter & Definition & Value & Reference \\
\hline$Z$ & Copepods & - & - \\
\hline$\beta$ & Maximum predation rate & $1 \mu g C l^{-1} \mathrm{~d}^{-1}$ & Edwards and Brindley (1999) \\
\hline$\xi$ & Extra infochemical mediated predation & $0.1 \mu g \mathrm{gl}^{-1} \mathrm{~d}^{-1}$ & - \\
\hline$k_{Z}$ & Half saturation constant & $30 \mu \mathrm{gCl}^{-1}$ & Morozov et al. (2011) \\
\hline$\epsilon$ & Predation efficiency & 0.7 & Edwards et al. (2000) \\
\hline$\mu$ & Microzooplankton natural mortality & $0.1 \mathrm{~d}^{-1}$ & Edwards and Brindley (1999) \\
\hline$\delta$ & Copepod mortality & $0.15 \mathrm{~d}^{-1}$ & Edwards and Brindley (1999) \\
\hline
\end{tabular}

infochemical-mediated refuge effect can be reproduced in a more realistic model, therefore strengthening our original result.

\subsection{Numerical simulations}

Numerical investigation of the modified model given by Eqs. (1), (2), (7) and (8), using the parameter values given in Tables $1 \& 3$, shows that the qualitatively important features of the simple model (Eqs. (1)-(3)) remain unchanged. In particular, when microzooplankton show no grazing selectivity $(g=0.5)$ solutions tend to a limit cycle around the unstable equilibrium $\left(0, \tilde{P}_{2}, \tilde{M}, \tilde{Z}\right)=$ $(0,3.812,5.380,0.710)$ for all competitive situations. Here, as in the model given by Eqs. (1)-(3), the infochemical producing phytoplankton quickly become extinct from the system, leaving non-infochemical producing phytoplankton, microzooplankton and copepod densities to oscillate over time (Fig. 7a). However, when infochemicals are modeled as strong grazing attractors for microzooplankton $(g>0.913)$ and the competitive effect of noninfochemical producing phytoplankton is weak $\left(\alpha_{12}=0.8\right)$ solutions tend to the asymptotically stable equilibrium $\left(P_{1}^{*}, P_{2}^{*}, M^{*}, Z^{*}\right)$
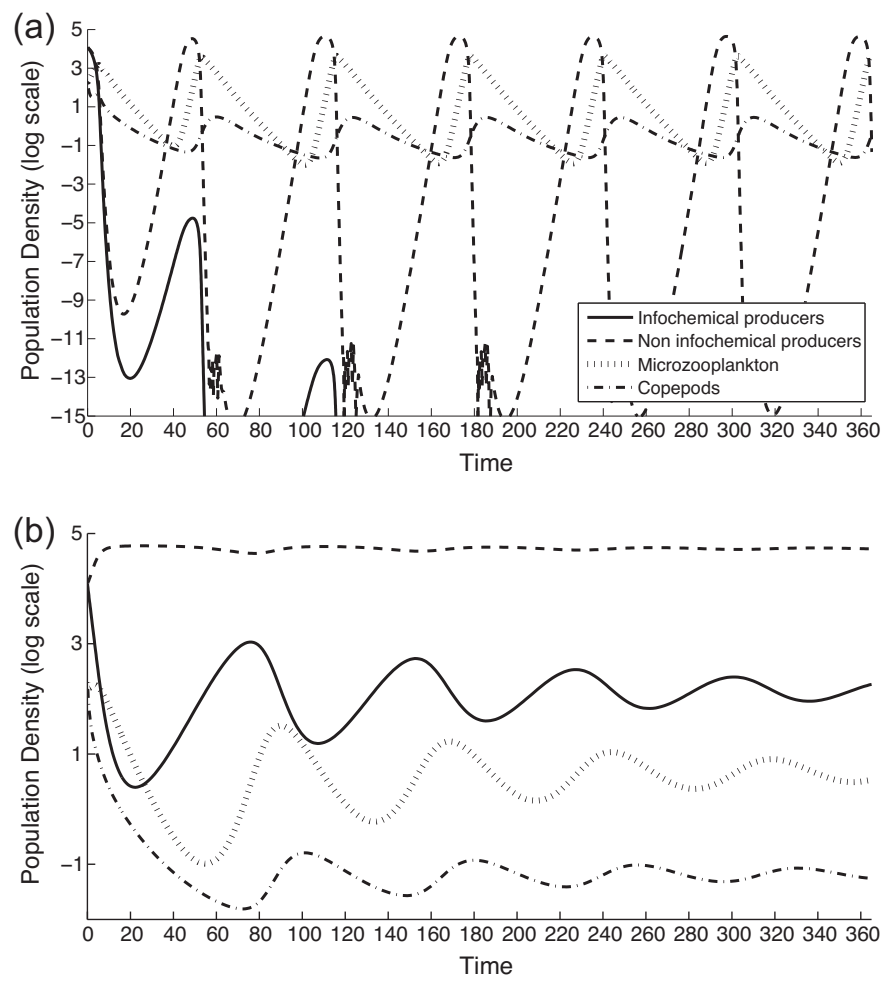

Fig. 7. Time series plots for the refined model when competition is weak $\left(\alpha_{12}=\alpha_{21}=0.8\right)$. (a) Microzooplankton show no grazing selectivity $(g=0.5)$. Solutions oscillate around the unstable equilibrium $(0,3.812,5.380,0.710)$. (b) Microzooplankton show high grazing attraction $(g=0.983)$. Solutions tend to the asymptotically stable equilibrium $(8.675,112.820,1.979,0.309)$. A similar plot is obtained when infochemical producers are parameterized as the superior competitors $\left(\alpha_{12}=0.8, \alpha_{21}=1.2\right)$. where $P_{1}^{*}, P_{2}^{*}, M^{*}, Z^{*} \neq 0$ for a large range of initial conditions (checked using Maple 12), corresponding to the coexistence of all plankton species (Fig. 7b).

\subsection{Bifurcation analysis}

Bifurcation analyses performed for both cases where noninfochemical producing phytoplankton are weak competitors $\left(\alpha_{12}=0.8\right)$ produce results analogous to those obtained from the simple model given by Eqs. (1)-(3). The stable limit cycle around $E_{5 c}=\left(0, \tilde{P}_{2}, \tilde{M}, \tilde{Z}\right)$, that occurs when microzooplankton show no grazing selectivity, is destroyed by a supercritical Hopf bifurcation at $g=0.871$, stabilizing this equilibrium. A transcritical bifurcation at $g=0.913$ then transfers stability from $E_{5 c}$ to $E_{6 c}=\left(P_{1}^{*}, P_{2}^{*}, M^{*}, Z^{*}\right)$
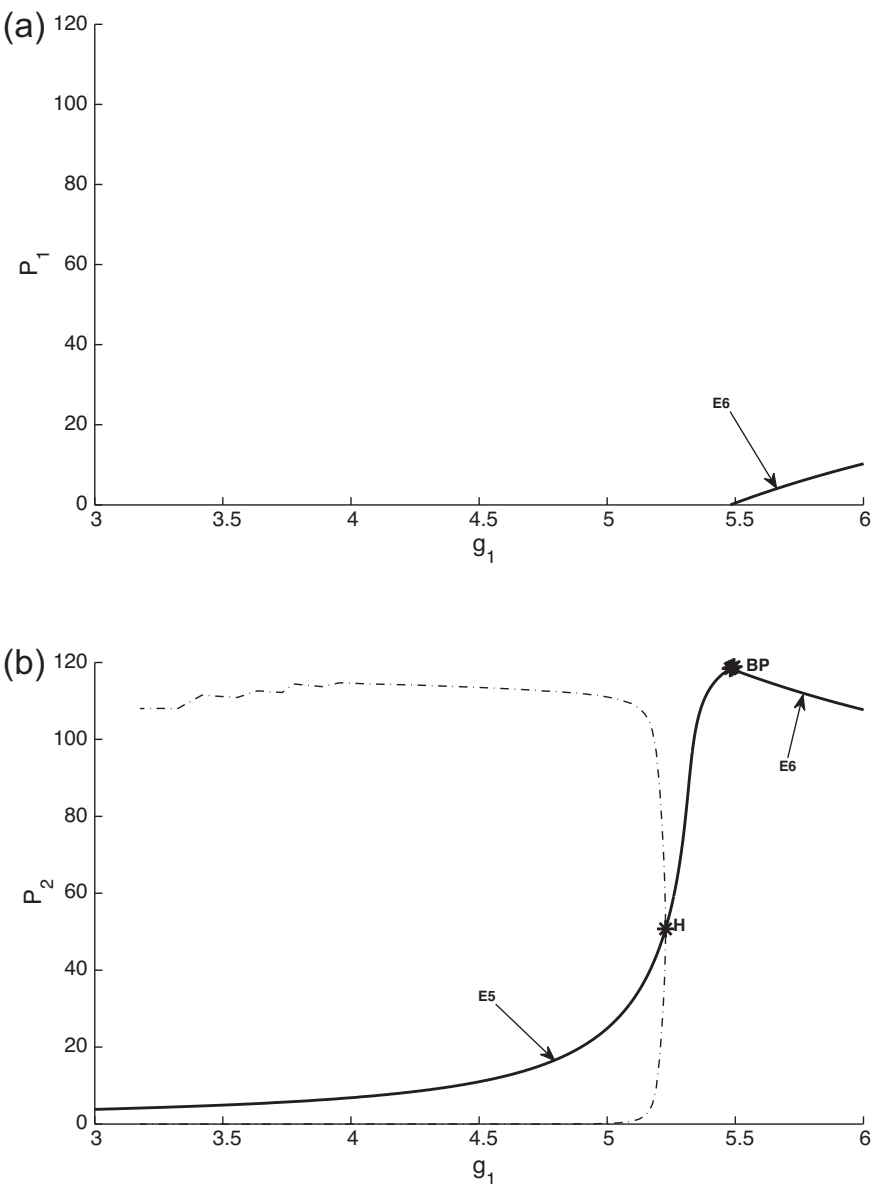

Fig. 8. Bifurcation diagram for (a) $P_{1}$ and (b) $P_{2}$ when microzooplankton chemoattraction is increased and infochemical producers are the superior competitors $\left(\alpha_{12}=0.8, \alpha_{21}=1.2\right)$. The dot-dashed line shows the magnitude of the limit cycle when $E_{5}$ is unstable. $\mathrm{H}=$ Hopf; $\mathrm{BP}=$ branch point (transcritical bifurcation). A similar diagram is obtained when competition is weak $\left(\alpha_{12}=\alpha_{21}=0.8\right)$. Note that branches corresponding to permanently unstable equilibria have been omitted. 
where $P_{1}^{*}, P_{2}^{*}, M^{*}, Z^{*} \neq 0$, that is where all plankton species coexist (Fig. 8).

These results strengthen the key result from analysis of the simple model; that the release of chemoattractants may create a grazing refuge for the producer through the promotion of multitrophic interactions. The fact that these results can be reproduced in a more complex and realistic model add to the robustness of the result.

\section{Discussion}

Here we use a competition model to investigate the effect of infochemicals in modifying microzooplankton grazing selectivity. In addition, we consider the potential of grazing-induced infochemicals modifying microzooplankton susceptibility to predation in a multi-trophic scenario.

Addition of a predator to a simple competitive situation has traditionally been proposed to promote coexistence between competing prey (Paine, 1966) and prevent one species heading to extinction as predicted by the principle of competitive exclusion (Hardin, 1960). In our model (using the parameter values given in Tables 1 and 3), a grazer showing no grazing selectivity in response to chemical cues resulted in the extinction of infochemical producing phytoplankton as a result of reduced growth rates, with the remaining plankton species exhibiting oscillations in population density. Previous studies of two-competitor one predator models have shown that such a system can be stabilized if one of the prey species is inedible (Kretzschmar et al., 1993) or toxic (Roy et al., 2006; Roy and Chattopadhyay, 2006). Here, a similar result is obtained when microzooplankton, subject to higher trophic predation, preferentially graze phytoplankton in response to infochemical cues and coexistence of all plankton species was possible.

In monospecific grazing trials Strom et al. (2003a) noted reduced microzooplankton grazing rates on strains of high DMSproducing phytoplankton, suggesting that DMS and related compounds function as grazing deterrents, thus forming an antigrazing mechanism (Wolfe et al., 1997). In the field, reduced grazing rates on high infochemical producing phytoplankton may allow the propagation of a bloom (Strom, 2008). However, field evidence for microzooplankton selectivity based on phytoplankton infochemical characteristics shows a high degree of variability (Archer et al., 2001b; Holligan et al., 1993; Olson and Strom, 2002).

The idea of an induced chemical defense in unicellular marine algae is a subject under debate. This idea is highly controversial because natural selection maximizes fitness at the level of the individual (Krebs, 2009). In the marine environment, individual cells lack fixed spatial associations and, therefore, despite the occurrence of genetically identical daughter cells, grazing-induced infochemicals are not selectively targeted (Lewis, 1986). Consequently, the benefits of the chemical defense would be shared not only by genetically similar cells but also by cells of other competing phytoplankton species. This is not an evolutionary stable strategy as it gives rise to 'cheaters' who gain the benefits of the chemical defense without the metabolic costs of its production (Lewis, 1986), illustrated by reduced growth rates in this model. However, some chemicals proposed to have defensive functions, such as DMS and related compounds, also serve several intracellular functions (e.g. Malin and Kirst, 1997; Sunda et al., 2002). It has therefore been proposed that marginal fitness benefits of such defense mechanisms are driven by the need for metabolic processes (Pohnert et al., 2007).

To our knowledge, this work presents the first attempt to model infochemicals as chemoattractants in a phytoplankton competition model. When infochemicals were modeled as grazing attractors, a range of different scenarios could occur depending on competitive coefficients and grazing selectivity. Our key result is that when microzooplankton showed no selectivity in the model $(g=0.5)$ infochemical producing phytoplankton were always driven to extinction, but when these phytoplankton produce chemoattractants that increase their own susceptibility to grazing it was possible for the infochemical producing population to survive in the system. This counterintuitive result can be explained through the promotion of multitrophic interactions; the release of grazinginduced infochemicals increases the susceptibility of microzooplankton to copepod predation, thus providing a grazing refuge for infochemical-producing phytoplankton. This situation may occur in the plankton where DMS has been shown to stimulate foraging behaviors in copepods (Steinke et al., 2006). Small DMS-producing phytoplankton such as Emiliania huxleyi are grazed inefficiently by copepods (Nejstgaard et al., 1997), however, microzooplankton grazing-induced production of DMS may provide E. huxleyi with a refuge from grazing. This result is supported by Lewis et al. (2012) who modeled infochemical-mediated multi-trophic interactions in the absence of a competing algal species.

Chemical cues play important roles in the structure and functioning of marine food webs (Hay, 2009), However, in many cases the infochemicals that affect the behavior of planktonic organisms are poorly understood (Pohnert et al., 2007). The model presented here gives an insight into the possible functions of infochemicals in the ecology of marine planktonic food webs, and supports the notion that infochemicals have potentially important consequences for the dynamics of marine food webs.

\section{Acknowledgement}

This work was funded by a grant from the UK Natural Environment Research Council (NERC; NE/H009485/1).

\section{References}

Archer, S.D., Stelfox-Widdicombe, C.E., Burkill, P.H., Malin, G., 2001a. A dilution approach to quantify the production of dissolved dimethylsulphoniopropionate and dimethyl sulphide due to microzooplankton herbivory. Aquatic Microbial Ecology 23, 131-145.

Archer, S.D., Widdicombe, C.E., Tarran, G.A., Rees, A.P., Burkill, P.H., 2001b. Production and turnover of particulate dimethylsulphoniopropionate during a coccolithophore bloom in the northern North Sea. Aquatic Microbial Ecology 24, 225241.

Archer, S.D., Stelfox-Widdicombe, C.E., Malin, G., Burkill, P.H., 2003. Is dimethyl sulphide production related to microzooplankton herbivory in the southern North Sea? Journal of Plankton Research 25, 235-242.

Bairagi, N., Pal, S., Chatterjee, S., Chattopadhyay, J., 2008. Nutrient, non-toxic phytoplankton, toxic phytoplankton and zooplankton interaction in an open marine system. In: Hosking, R.J., Venturino, E. (Eds.), Aspects of Mathematical Modelling. Birkhäuser, Switzerland, pp. 41-63.

Banerjee, M., Venturino, E., 2011. A phytoplankton-toxic phytoplankton-zooplankton model. Ecological Complexity 8, 239-248.

Breckels, M.N., Roberts, E.C., Archer, S.D., Malin, G., Steinke, M., 2011. The role of dissolved infochemicals in mediating predator-prey interactions in the heterotrophic dinoflagellate Oxyrrhis marina. Journal of Plankton Research 33, 629639.

Calbet, A., Landry, M.R., 2004. Phytoplankton growth, microzooplankton grazing, and carbon cycling in marine systems. Limnology and Oceanography 49, 51-57.

Coleman, R.A., Ramchunder, S.J., Davies, K.M., Moody, A.J., Foggo, A., 2007. Herbivore-induced infochemicals influence foraging behaviour in two intertidal predators. Oecologia 151, 454-463.

Davidson, K., Sayegh, F., Montagnes, D.J.S., 2011. Oxyrrhis marina-based models as a tool to interpret protozoan population dynamics. Journal of Plankton Research 33, 651-663.

Dhooge, A., Govaerts, W., Kuznetsov, Y.A., 2003. MATCONT: a MATLAB package for numerical bifurcation analysis of ODEs. ACM Transactions on Mathematical Software 29, 141-164.

Dicke, M., 1999. Evolution of induced indirect defense of plants. In: Tollrian, R., Harvell, C.D. (Eds.), The Ecology and Evolution of Inducible Defenses. Princeton University Press, Princeton, NJ, pp. 62-88.

Edwards, A.M., Brindley, J., 1999. Zooplankton mortality and the dynamical behaviour of plankton population models. Bulletin of Mathematical Biology 61, 303339.

Edwards, A.M., Yool, A., 2000. The role of higher predation in plankton population models. Journal of Plankton Research 22, 1085-1112. 
Edwards, C.A., Batchelder, H.P., Powell, T.M., 2000. Modeling microzooplankton and macrozooplankton dynamics within a coastal upwelling system. Journal of Plankton Research 22, 1619-1648.

Freedman, H.I., Waltman, P., 1984. Persistence in models of three interacting predator-prey populations. Mathematical Biosciences 68, 213-231.

Hardin, G., 1960. The competitive exclusion principle. Science 131, 1292-1297.

Hay, M.E., 2009. Marine chemical ecology: chemical signals and cues structure marine populations, communities, and ecosystems. Annual Review of Marine Science 1, 193-212.

Holligan, P.M., Fernández, E., Aiken, J., Balch, W.M., Boyd, P., Burkill, P.H., Finch, M., Groom, S.B., Malin, G., Muller, K., Purdie, D.A., Robinson, C., Trees, C.C., Turner, S.M., van der Wal, P., 1993. A biogeochemical study of the coccolithophore, Emiliania huxleyi, in the North Atlantic. Global Biogeochemical Cycles 7, 879900.

Irigoien, X., Flynn, K.J., Harris, R.P., 2005. Phytoplankton blooms: a 'loophole’ in microzooplankton grazing impact? Journal of Plankton Research 27, 313321.

Klein Breteler, W.C.M., Schogt, N., Bass, M., Schouten, S., Kraay, G.W., 1999. Trophic upgrading of food quality by protozoans enhancing copepod growth: role of essential lipids. Marine Biology 135, 191-198.

Krebs, C.J., 2009. Ecology, 6th ed. Pearson, San Francisco.

Kretzschmar, M., Nisbet, R.M., McCauley, E., 1993. A predator-prey model for zooplankton grazing on competing algal populations. Theoretical Population Biology 44, 32-66.

Lewis, W.M., 1986. Evolutionary interpretations of allelochemical interactions in phytoplankton algae. American Naturalist 127, 184-194.

Lewis, N.D., Breckels, M.N., Archer, S.D., Morozov, A., Pitchford, J.W., Steinke, M., Codling, E.A., 2012. Grazing-induced production of DMS can stabilize food-web dynamics and promote the formation of phytoplankton blooms in a multitrophic plankton model. Biogeochemistry 110, 303-313.

Malin, G., Kirst, G.O., 1997. Algal production of dimethyl sulfide and its atmospheric role. Journal of Phycology 33, 889-896.

Maple 12, 2008. Maplesoft. A Division of Waterloo Maple Inc., Waterloo, Ontario.

MathWorks Inc., MATLAB: The Language of Technical Computing, version 7.8. 2009, MathWorks, Natick, MA.

Morozov, A., Arashkevich, E., Nikishina, A., Solovyev, K., 2011. Nutrient-rich plankton community stabilized via predator-prey interactions: revisiting the role of vertical heterogeneity. Mathematical Medicine and Biology 28, 185-215.

Murray, J.D., 2002. Mathematical Biology I, 2nd ed. Springer, New York.

Nejstgaard, J.C., Båmstedt, U., Bagøien, E., Solberg, P.T., 1995. Algal constraints on copepod grazing. Growth state, toxicity, cell size and season as regulating factors. ICES Journal of Marine Science 52, 347-357.

Nejstgaard, J.C., Gismervik, I., Solberg, P.T., 1997. Feeding and reproduction by Calanus finmarchicus and microzooplankton grazing during mesocosm blooms of diatoms and the coccolithophore Emiliania huxleyi. Marine Ecology Progress Series 147, 197-217.

Olson, M.B., Strom, S.L., 2002. Phytoplankton growth, microzooplankton herbivory and community structure in the southeast Bering Sea: insight into the formation and temporal persistence of an Emiliania huxleyi bloom. Deep Sea Research II 49, 5969-5990.

Paine, R.T., 1966. Food web complexity and species diversity. American Naturalist $100,65-75$

Pal, S., Chatterjee, S., Das, K.P., Chattopadhyay, J., 2009. Role of competition in phytoplankton population for the occurrence and control of plankton bloom in the presence of environmental fluctuations. Ecological Modelling 220, 96-110.
Pohnert, G., Steinke, M., Tollrian, R., 2007. Chemical cues, defence metabolites and the shaping of pelagic interspecific interactions. Trends in Ecology \& Evolution 22, 198-204.

Roberts, E.C., Wooton, E.C., Davidson, K., Jeong, H.J., Lowe, C.D., Montagnes, D.J.S., 2011. Feeding in the dinoflagellate Oxyrrhis marina: linking behaviour with mechanisms. Journal of Plankton Research 33, 603-614.

Rosenzweig, M.L., MacArthur, R.H., 1963. Graphical representation and stability conditions of predator-prey interactions. American Naturalist 97, 209-223.

Roy, S., Alam, S., Chattopadhyay, J., 2006. Competing effects of toxin-producing phytoplankton on the overall plankton populations in the Bay of Bengal. Bulletin of Mathematical Biology 68, 2303-2320.

Roy, S., Chattopadhyay, J., 2006. Enrichment and ecosystem stability: effect of toxic food. Biosystems 90, 151-160.

Seymour, J.R., Simo, R., Ahmed, T., Stocker, R., 2010. Chemoattraction to dimethylsulfoniopropionate throughout the marine microbial foodweb. Science 329 , 342-345.

Sherr, E., Sherr, B., 1988. Role of microbes in pelagic food webs. Limnology and Oceanography 33, 1225-1227.

Solé, J., Garcia-Ladona, E., Estrada, M., 2006. Role of selective predation in harmful algal blooms. Journal of Marine Systems 62, 46-54.

Steinke, M., Malin, G., Liss, P.S., 2002. Trophic interactions in the sea: an ecological role for climate relevant volatiles? Journal of Phycology 38, 630-638.

Steinke, M., Stefels, J., Stamhuis, E., 2006. Dimethyl sulfide triggers search behaviour in copepods. Limnology and Oceanography 51, 1925-1930.

Strickler, J.R., 1982. Calanoid copepods, feeding currents, and the role of gravity. Science 218, 158-160

Strom, S.L., 2008. Microbial ecology of ocean biogeochemistry: a community perspective. Science 320, 1043-1045.

Strom, S., Wolfe, G., Holmes, J., Stecher, H., Shimeneck, C., Lambert, S., Moreno, E. 2003a. Chemical defense in the microplankton I: feeding and growth rates of heterotrophic protists on the DMS-producing phytoplankter Emiliania huxleyi. Limnology and Oceanography 48, 217-229.

Strom, S., Wolfe, G., Slajer, A., Lambert, S., Clough, J., 2003b. Chemical defense in the microplankton II: Inhibition of protist feeding by $\beta$-dimethylsulfoniopropionate (DMSP). Limnology and Oceanography 48, 230-237.

Sunda, W., Kieber, D.J., Kiene, R.P., Huntsman, S., 2002. An antioxidant function for DMSP and DMS in marine algae. Nature 418, 317-320.

Tang, K.W., Taal, M., 2005. Trophic modification of food quality by heterotrophic protists: species specific effects on copepod egg production and egg hatching. Journal of Experimental Marine Biology and Ecology 318, 85-98.

Turner, J.T., Tester, P.A., 1997. Toxic marine phytoplankton, zooplankton grazers, and pelagic food webs. Limnology and Oceanography 42, 1203-1214.

Vos, M., Vet, L.E.M., Wäckers, F.L., Middelburg, J.J., van der Putten, W.H., Mooij, W.M. Heip, C.H.R., van Donk, E., 2006. Infochemicals structure marine, terrestrial and fresh water food webs, implications for ecological informatics. Ecological Informatics 1, 23-32.

Waltman, P., 1983. Competition Models in Population Biology. SIAM, Philadelphia, PA.

Wolfe, G.V., 2000. The chemical defense ecology of marine unicellular plankton: constraints, mechanisms and impacts. Biological Bulletin 198, 225-244.

Wolfe, G.V., Steinke, M., 1996. Grazing-activated production of dimethyl sulfide (DMS) by two clones of Emiliania huxleyi. Limnology and Oceanography 41 1151-1160.

Wolfe, G.V., Steinke, M., Kirst, G.O., 1997. Grazing-activated chemical defence in a unicellular marine alga. Nature 387, 894-897. 